\title{
Allergy and occupational exposure to hydroquinone and to methionine
}

\author{
D CHOUDAT, ${ }^{\prime}$ F NEUKIRCH, ${ }^{2}$ P BROCHARD,${ }^{3}$ G BARRAT, ${ }^{\prime}$ J MARSAC,${ }^{4}$ F CONSO,${ }^{1}$ \\ M PHILBERT ${ }^{1}$
}

From the Service de pathologie professionnelle,' Hôpital Cochin, 75014 Paris, Institut National de la Santé et de la Recherche Médicale, ${ }^{2}$ Unité 179, 78110 Le Vésinet, Service de pneumologie, ${ }^{3}$ Centre Hospitalier InterCommunal de Créteil, 94010 Créteil Cedex, and Service de pneumologie, ${ }^{4}$ Hôpital Cochin, 75014 Paris, France

\begin{abstract}
Respiratory manifestations have been reported after exposure to hydroquinone and to methionine. One hundred and three men in the same chemical plant were divided into three groups according to their exposure and compared by questionnaire, respiratory functional tests with methacholine then salbutamol challenges, and measurements of serum immunoglobulins $\mathrm{G}$ and $\mathrm{E}$. Group $\mathrm{H}$ included 33 workers exposed to hydroquinone, trimethyl-hydroquinone, and retinenehydroquinone. Group $\mathrm{M}$ included 15 workers exposed to methionine. Group $\mathrm{C}$ was a control group of 55 workers. The prevalence of respiratory symptoms was higher in the two exposed groups. Before challenges, pulmonary function values were significantly lower in groups $\mathbf{H}$ and $\mathbf{M}$ than those in group $\mathrm{C}$. The challenges induced significant variations in the three groups but these variations were less pronounced in group $\mathbf{M}$ than in the other groups. The level of immunoglobulin $\mathbf{G}$ in group $\mathbf{H}$ $(\mathrm{m} \pm \mathrm{SD}=12.5 \mathrm{~g} / 1 \pm 2.6)$ was significantly higher than in group $\mathrm{C}(10.6 \mathrm{~g} / 1 \pm 2.4 ; \mathrm{p}<0.002)$. The level of immunoglobulin $\mathrm{E}$ in group $\mathrm{H}(\mathrm{m}=140 \mathrm{IU} / \mathrm{l})$ was also higher in group $\mathrm{C}(109 \mathrm{IU} / \mathrm{l})$ but this difference was not significant. These findings suggest that exposure to methionine and to hydroquinone and its derivatives induce ventilatory impairment, perhaps by an immunological mechanism.
\end{abstract}

Many chemicals may induce bronchial obstruction. In the past three years three cases of dyspnoea with airways obstruction after exposures to hydroquinone and to methionine were observed in a chemical plant.' A few cases of dermatitis were reported after exposure to hydroquinone $\mathrm{e}^{2-4}$; no other case of toxicity or of allergy after exposure to methionine has been described. ${ }^{s}$

The aim of the present study was to compare the effects of these occupational exposures with a control group for (1) the prevalence of respiratory symptoms and ventilatory impairment, (2) the variations in pulmonary function after the inhalation of methacholine and salbutamol, and (3) the blood levels of immunoglobulins $\mathbf{G}$ and $\mathrm{E}$.

Accepted 11 May 1987

\section{Methods}

The study population was composed of workers in a large chemical plant engaged in the synthesis of methionine and vitamins.

\section{POPULATION}

One hundred and three men worked in shifts for continuous production. A three shift system was operated. The first shift began at 0400 and finished at 1200 , the second ran from 1200 to 2000 , and the third from 2000 to 0400 . The shifts alternated each week. The workers were divided into three groups according to the exposure in their current job. Group $\mathbf{H}$ included 33 workers exposed to hydroquinone, trimethylhydroquinone and retinene-hydroquinone. Group M included 15 workers exposed to methionine. Group $\mathrm{C}$ was a control group and included 55 workers of the same socioprofessional status in the same plant. They were matched with the exposed groups before the 
study on age and were not exposed to any significant air contaminants in the plant.

\section{QUESTIONNAIRE}

A questionnaire was completed by trained interviewers. It contained questions on individual characteristics such as age, height, weight, race, medical history, and work history in the plant and before employment in the plant. Non-smokers were defined as having a lifelong abstinence from smoking and exsmokers as those who had ceased smoking completely at least six months before the study. The questions on respiratory symptoms of the British Medical Research Council's standard questionnaire on chronic bronchitis were translated and questions related to symptoms arising during work or as a result of acute exposure to fog, fumes, or wind were included. The questionnaire, tested before the study, took about 15 minutes to complete.

\section{PULMONARY FUNCTION TESTS}

Measurement of pulmonary function was carried out at the worksite using a computerised pneumotachograph Fleish No 3 (Spiromatic, MSR) which was calibrated daily. The forced expiration was followed on an oscilloscope. At least three readings were obtained with the worker seated and wearing a noseclip. The curve producing the largest sum of forced expiratory volume in one second $\left(\mathrm{FEV}_{1}\right)$ and forced vital capacity (FVC) were selected for analysis. The other standard pulmonary function parameters were recorded from this best maximal expiratory flow volume curve: peak flow rate, forced expiratory flow during the middle half of the FVC, maximal flow rate at $25 \%, 50 \%$, and $75 \%$ of exhaled FVC. All values were adjusted for age and height using regressions on the whole sample and normalised $(\mathrm{m} \pm \mathrm{SD}=0 \pm 1)$.

All but three workers agreed to take part. For each subject spiromatic measurements were performed three times by the same experienced technicians: at least two hours after the beginning of the workshift (T1), just after inhalation of $200 \mu \mathrm{g}$ of methacholine (T2), and 15 minutes after the inhalation of $100 \mu \mathrm{g}$ of salbutamol (T3). The questionnaire was completed between the inhalation of salbutamol and the third measurement. The aerosol of methacholine was delivered by an Aerosolan nebuliser (MSR). A storage bell was filled with the methacholine aerosol immediately before use. Each subject inhaled a fixed volume from the bell through a mouth piece. ${ }^{6}$

\section{BIOLOGICAL DATA}

Samples of venous blood were collected from the 33 workers exposed to hydroquinone and from 44 control subjects at a separate time from the pulmonary function measurements. Several measurements were done: blood cells, erythrocyte sedimentation rate, glutamyl transpeptidase, alkaline phosphatase, and immunoglobulins $\mathrm{G}$ and E. Serum immunoglobulin $\mathrm{E}$ concentrations were determined by the radioimmunosorbent technique (RIST, Phadebas) performed as recommended by Pharmacia Diagnostics AB, Uppsala. The immunoglobulin $\mathrm{E}$ concentrations are reported in international units (IU/l).

\section{STATISTICAL ANALYSIS}

Standard descriptive statistics were used to represent responses. Chi-squared tests were used with $2 \times 2$ contingency tables to determine whether relations shown between such variables were statistically significant. Analysis of variance was used to examine the relation of respiratory symptoms, work exposure, and smoking to pulmonary function.

\section{Results}

The subjects in groups $\mathrm{H}$ and $\mathrm{M}$ had a significantly higher prevalence of cough induced by a smoky atmosphere or by cold air than the controls. Cough at work was also more frequent in the two exposed groups. The other symptoms, smoking habits, and the characteristics of the population did not differ significantly between the three groups (tables 1 and 2).

At $\mathrm{T} 1$ all the pulmonary function values were lower in groups $\mathbf{H}$ and $M$ than in group $C$ (fig 1). The differences were significant in group $\mathrm{H}$ for $\mathrm{FEV}_{1}$; maximal flow rate at $50 \%, 75 \%$; forced expiratory

Table 1 Characteristics of the three groups: group C control workers, group $H$ workers exposed to hydroquinone, group $M$ workers exposed to methionine

\begin{tabular}{|c|c|c|c|c|}
\hline & Group $H$ & Group $M$ & Group C & $p$ \\
\hline $\begin{array}{l}\text { Age (years, } M \pm S D) \\
\text { Duration of employment } \\
\quad \text { (years } M \pm S D)\end{array}$ & $\begin{array}{l}39 \cdot 0 \pm 8 \cdot 4 \\
11 \cdot 7 \pm 6 \cdot 0\end{array}$ & $\begin{array}{l}39.2 \pm 6.9 \\
13.5 \pm 6.1\end{array}$ & $\begin{array}{l}40 \cdot 1 \pm 8 \cdot 1 \\
13 \cdot 8 \pm 5 \cdot 6\end{array}$ & NS \\
\hline $\begin{array}{l}\text { Smokers No (\%) } \\
\text { Ex-smokers No }(\%) \\
\text { Non-smokers No (\%) }\end{array}$ & $\begin{array}{r}17(51 \cdot 5 \%) \\
9(27 \cdot 3 \%) \\
7(21 \cdot 2 \%)\end{array}$ & $\begin{array}{c}10(66 \cdot 7 \%) \\
2(13 \cdot 3 \%) \\
3(20 \%)\end{array}$ & $\begin{array}{l}25(45.4 \%) \\
17(30.9 \%) \\
13(23.6 \%)\end{array}$ & $\begin{array}{l}\text { NS } \\
\text { NS }\end{array}$ \\
\hline
\end{tabular}

Table 2 Prevalence of symptoms in exposed workers and controls

\begin{tabular}{llll}
\hline & Group $H$ & Group $M$ & Group C \\
\hline No of workers & 33 & 15 & 55 \\
Chronic cough & $0 \%$ & $7 \%$ & $9 \%$ \\
Cough in a smoky atmosphere & $42 \% \%^{* *}$ & $33 \%$ & $16 \%$ \\
Asthma & $3 \%$ & 13 & $2 \% *$ \\
Eczema & $30 \%$ & $0 \%$ & $20 \%$ \\
Hay fever & $36 \% *$ & $27 \%$ & $18 \%$ \\
Work related symptoms & $24 \% \%^{* * *}$ & $27 \%$ & $7 \% * *$ \\
\hline "p $<0.05 ;{ }^{* *} \mathrm{p}<0 \cdot 01 ;{ }^{* * *} \mathrm{p}<0.001$
\end{tabular}




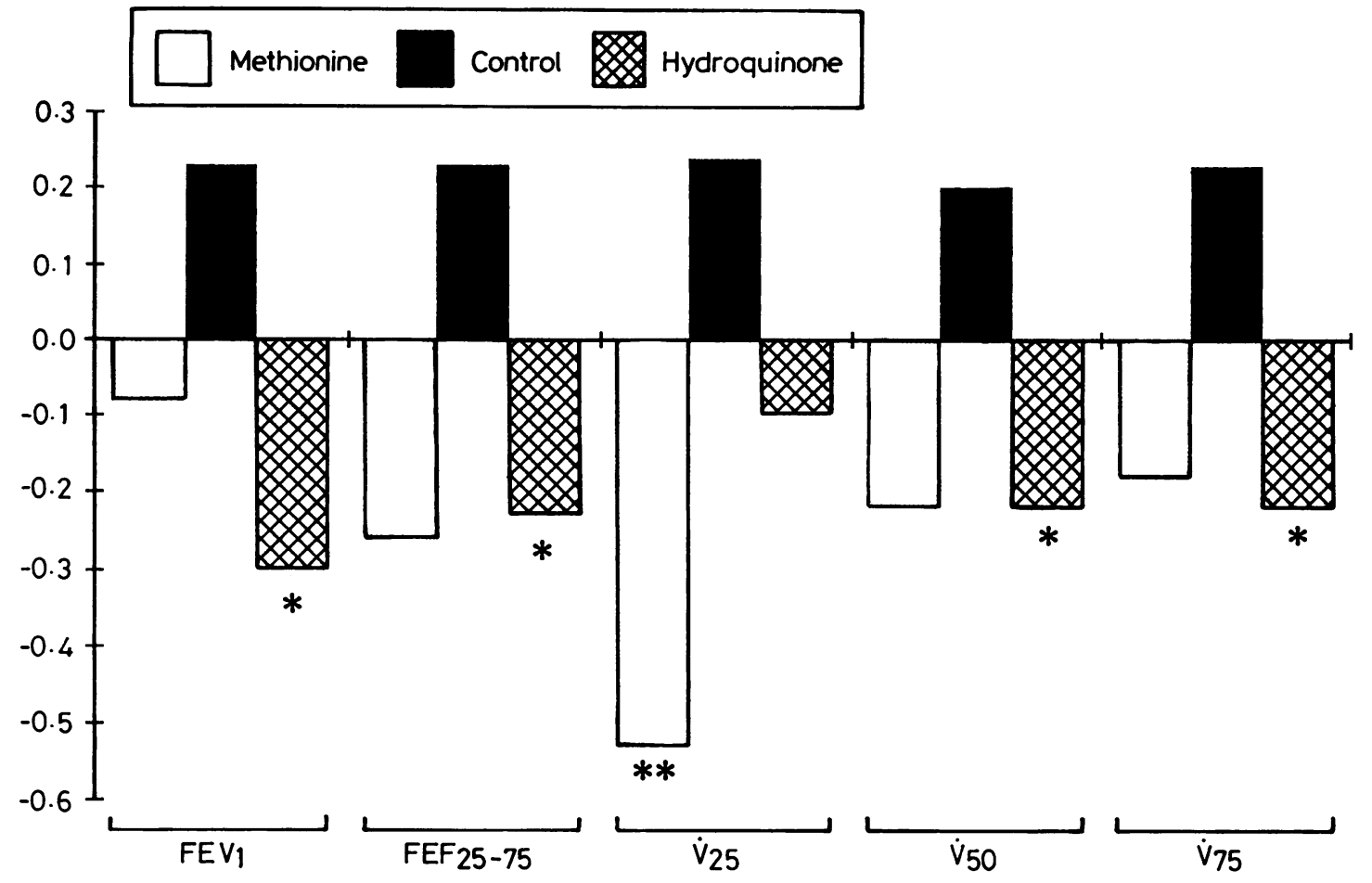

Fig 1 Mean pulmonary function values according to exposure. Values are adjusted for age and height: observed-predicted values/residual $S D .{ }^{*} p<0.01 ;{ }^{* *} p<0.001$.

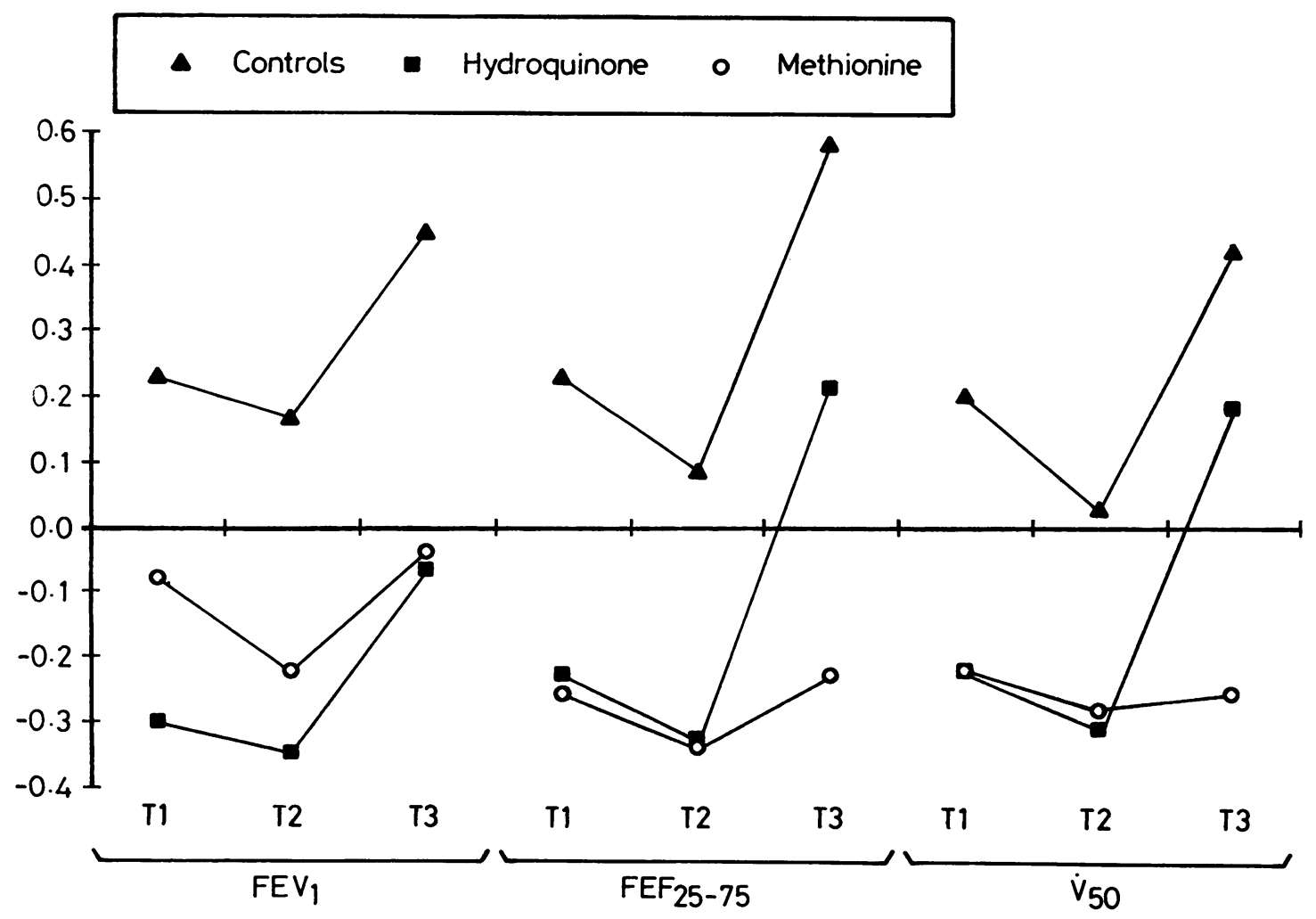

Fig 2 Evolution of pulmonary function challenge with methacholine then salbutamol. 
flow during the middle half of the FVC; and in group $\mathbf{M}$ for maximal flow rate at $25 \%$. All these significant differences remained after adjustment for tobacco consumption.

The pharmacological tests induced similar variations in the exposed and the control groups. The flow rates decreased slightly after the inhalation of methacholine and increased after the inhalation of salbutamol (fig 2). These variations between T1 T2 and between T2 T3 were significant. They were less pronounced in group $\mathbf{M}$ than in the other groups.

The level of immunoglobulin $G$ in group $H$ $(\mathrm{m} \pm \mathrm{SD}=12.5 \mathrm{~g} / 1 \pm 2.6)$ was higher than in group $\mathrm{C}$ $(10.6 \mathrm{~g} / 1 \pm 2 \cdot 4)$. This difference is significant $(p<0.002)$. The level of immunoglobulin $E$ in group $\mathrm{H}(\mathrm{m}=140 \mathrm{IU} / \mathrm{l})$ was also higher than in group $\mathrm{C}(109$ IU/l) but this difference was not significant. The other laboratory data were similar in both groups.

\section{Discussion}

The prevalence of respiratory symptoms was higher in the two exposed groups than in the control group. The symptoms were also different in the two exposed groups: the prevalence of allergic symptoms was higher in group $\mathrm{H}$ whereas the prevalence of chronic respiratory symptoms was higher in group $\mathbf{M}$. Moreover, the bronchodilator test showed a better reversibility of the impairment of the respiratory function in group $\mathrm{H}$ than in group $\mathrm{M}$. So it seems that hydroquinone, or its derivatives, induces intermittent dyspnoea and reversible obstruction as an allergic response whereas methionine dust induces chronic cough and airway obstruction-industrial bronchitis.

In the present study a single dose of methacholine was used for the bronchoconstrictor challenge. This low dose $(200 \mu \mathrm{g})$ could induce a significant decrease in the air flow in the exposed groups and also in the control group. Similar findings were described by Pham and coworkers using $1200 \mu \mathrm{g}$ of acetylcholine in iron mine workers.? They confirmed, with a prospective study, the use of a test of bronchial hyperreactivity as a means of identifying subjects at risk from chronic obstructive lung disease. Cookson and his coworkers studied seasonal grain handlers. ${ }^{8}$ There was a statistically significant association between bronchial reactivity at the beginning of the season and the frequency of work related symptoms. But these two studies did not take into account the variations induced by the challenge in non-exposed workers. They found subgroups of reactive subjects among the exposed workers but had no comparison with non-exposed controls.

A single dose may be easily performed in an epidemiological study. But the choice of the dose may be difficult:

a lower dose may be unable to distinguish hyperreactivity induced by the occupational exposure;

a higher dose may induce severe bronchospasm among asthmatic patients.

The choice depends on the aim of the study: the determination of subgroups of hyperreactive subjects among one population needs higher doses. A comparison with control subjects may be performed with lower doses, even if some hyperreactive patients are misdiagnosed.

Several mechanisms are probably involved in the allergic manifestations induced by occupational exposures. In some patients an increase of specific immunoglobulins $G$ and $E$ has been shown for isocyanate, ${ }^{910}$ hexahydrophthalic anhydride, " and for trimellitic anhydride. ${ }^{12}$ By contrast, no relation was found between byssinosis and serum concentrations of total immunoglobulins $\mathrm{E},{ }^{13}$ but the mechanism of byssinosis is not yet clear and is probably not mediated by immunoglobulin $\mathrm{E}$.

In conclusion, (1) exposure to hydroquinone and its derivatives and to methionine induces ventilatory impairment, (2) the results of the study justify the use of challenge tests in epidemiological surveys to differentiate the prevalence of bronchial hyperreactivity among exposed and non-exposed groups of workers, and (3) the higher levels of immunoglobulins $\mathrm{G}$ and $\mathrm{E}$ among workers exposed to hydroquinone and its derivatives needs to be assessed by measuring specific antibodies.

We thank Mrs E Leib, J de Palmas, B Najac, and M Korobaeff for technical help and Miss C Dufour and Mrs MJ Degrave for the typing and the figures. We also thank Mrs M Bidet, B Gaillot, M Ligocki.

Supported by grants from comités départementaux contre les maladies respiratoires et la tuberculose (No 83-A 3) and from Institut National de la Santé et de la Recherche Médicale (No 8380 21).

\section{References}

1 Barrat G, Choudat D, Brochard P, Marsac J, Philbert M. A propos de quelques observations d'asthmes professionnels. Archives des Maladies Professionelles de Médecine du Travail et de Sécurité Sociale 1984;44:53-4.

2 Nissen JN, Corydon L. Corneal ulcer after exposure to vapours from bone cement (methyl methacrylate and hydroquinone). Int Arch Occup Environ Health 1985;56:161-5.

3 Kersey P, Stevenson CJ. Vitiligo and occupational exposure to hydroquinone from servicing self-photographing machines. Contact Dermatitis 1981;7:285-7.

4 Stevenson CJ. Occupational vitiligo: clinical and epidemiological aspects. Br J Dermatol 1981;105 suppl 21:51-6.

5 Benevenga NJ. Toxicities of methionine and other amino acids. Journal of Agriculture Food and Chemicals 1974;22:1-9.

6 SEPCR Working group "Bronchial hyperreactivity," Eiser NN, Kerrebijn KF, Quanjer PH. Guidelines for standardization of bronchial challenges with (non-specific) bronchoconstricting 
agents. Bull Europ Physiopath Respir 1983;19:495-514.

7 Pham QT, Mur JM, Chau N, Gabiano M, Henquel JC, Teculescu D. Prognostic value of acetylcholine challenge test: a prospective study. Br J Ind Med 1984;41:267-71.

8 Cookson WOCM, Ryan G, Macdonald S, Musk AW. Atopy, non-allergic bronchial reactivity, and past history as determinants of work related symptoms in seasonal grain handlers. $\mathrm{Br} \mathrm{J}$ Ind Med 1986;43:396-400.

9 Baur X, Dewair M, Fruhmann G. Detection of immunologically sensitized isocyanate workers by RAST and intracutaneous skin tests. J Allergy Clin Immunol 1984;73:610-8.

10 Tse KS, Johnson A, Chan H, Chan-Yeung M. A study of serum antibody activity in workers with occupational exposure to diphenylmethane diisocyanate. Allergy 1985;40:314-20.

11 Moller DR, Gallagher JS, Bernstein DI, Wilcox TG, Burroughs HE, Bernstein IL. Detection of IgE-mediated respiratory sensitization in workers exposed to hexahydrophthalic anhydride. J Allergy Clin Immunol 1985;75:663-72.

12 Akiyama K, Pruzansky JJ, Patterson R. Hapten-modified basophils: a model of human immediate hypersensitivity that can be elicited by IgG antibody. J Immunol 1984;133:3286-90.

13 Petronio L, Bovenzi M. Byssinosis and serum IgE concentrations in textile workers in an Italian cotton mill. $\mathrm{Br} \mathrm{J}$ Ind Med 1983;40:39-44.

\section{Destruction of manuscripts}

From 1 July 1985 articles submitted for publication will not be returned. Authors whose papers are rejected will be advised of the decision and the manuscripts will be kept under security for three months to deal with any inquiries and then destroyed. 